\title{
N/Sก
}

National Aeronautics and Space Administration

\section{SPACE STATION EVOLUTION: PLANNING FOR THE FUTURE}

Prepared By

Alphonso V. Diaz

and

Barbara S. Askins

Prepared For

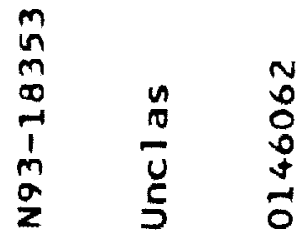

Acta Astronautic Space Station Special Issue

Office of Space Station

NASA Headquarters

Washington, D.C. 20546

June 23, 1987

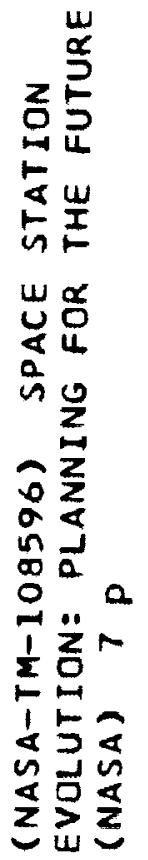

$\sum_{0}^{\infty}$ 
SPACE STATION EVOLUTION: PLANNING FOR THE FUTURE

\author{
Alphonso V. Diaz \\ Barbara S. Askins \\ NASA Headquarters \\ Code ST \\ Washington, DC 20546
}

The Space Station will have the capability to evolve on-orbit to greater capacities and capabilities to accommodate users and to support future national or international initiatives. Planning for Space Station evolution is a strategic management process to facilitate these changes. This objective is achieved by incorporating appropriate evolution provisions ("hooks and scars") in the baseline Space Station and by initiating an advanced development program to assure that the necessary technologies will be available for the evolution phases. Space Station evolution planning serves as a bridge between NASA long range planning and the baseline Space Station Program. The evolution advanced development program, on the other hand, serves as a bridge between generic technology development (particularly that sponsored by NASA's Office of Aeronautics and Space Technologyl and the baseline Space Station Program.

Central to the evolution planning process is the identification and study of options. These options include expansion of multidiscipline Station accommodations as well as specific growth paths to support new initiatives such as a piloted Mars mission or the establishment of a Lunar base. initially each option is studied independently to determine the future infrastructure required, the technology needs, and the "hooks and scars" on the baseline Station that will enable future exercise of the option. Subsequently, the results of these independent studies are examined as a group in order to derive the high leverage technologies and to identify actions that must be taken now to protect the future options.

The evolution planning process and the evolution advanced development program are conducted in a parallel and iterative manner. The advanced development program emphasizes both the development of high leverage evolution technologies and the incorporation of "technology opportunities" that will enhance evolution. Increased Space Station efficiency and productivity is recognized as a major benefit for all evolution options as well as a way to increase user accommodations without expanding the infrastructure. The evolution planning process includes studies of "technology transparency" to better understand how Space Station systems and subsystems should be designed to facilitate the incorporation of new technologies. And the evolution advanced development program includes the development of robotics and system autonomy capabilities that assure increased efficiency and productivity. The scope of the space Station evolution program thus includes the protection of options for growth and assurances of increased user services without substantial growth.

\section{Background and Introduction}

The need for permanently manned presence in space has been recognized by the United States and its international partners for many years. The development of this capability was delayed due to the concurrent recognition that reusable earth-toorbit transportation was also needed and should be developed first. While the decision to go ahead with a permanently manned Space Station was on hold, requirements for the use of the Station were accumulating as ground-based research and the data from unmanned spacecraft sparked the imagination of both scientists and entrepreneurs. Thus, by the time of the space Station implementation decision in the early 1980's, a variety of disciplines, with a variety of requirements, needed to be accommodated on one Space Station. Additional future requirements could be forecast for advanced missions that were still in the early planning stages. The logical response was the development of a multi-purpose Station Station with the ability to evolve on-orbit to new capabilities as required by user needs and national or international decisions, i.e. to build an evolutionary Space Station.

\section{Approach to Evolution Planning}

Planning for evolution is conducted in parallel with the design and development of the baseline Space Station. Evolution planning is a strategic management process to facilitate change and protect future decisions. The objective is not to forecast the future, but to understand the future options and the implications of these on today's decisions. The major actions required now are (1) the incorporation of evolution provisions ("hooks and scars") in the baseline Space Station and (2) the initiation of an evolution advanced development program.

The challenge is to understand the probable evolution paths and modes to the extent that current resources can be wisely allocated to the necessary "hooks and scars" and to the appropriate technology development efforts. This requires close coupling of evolution planning with mission planning, space and ground infrastructure planning, and technology development as well as with the baseline Space Station design and 
development activities. Therefore, with in NASA, evolution planning integrates important elements of strategic planning, long range mission and system planning, and the baseline Space Station program. The intersection of these domains of interest are shown in Figure 1. Integration of NASA evolution planning with that of the Space Station international partners is conducted in a parallel and iterative fashion. Additionally, evolution planning must consider possible commercial enterprises and other government agency requirements that may affect the course of Space Station growth.

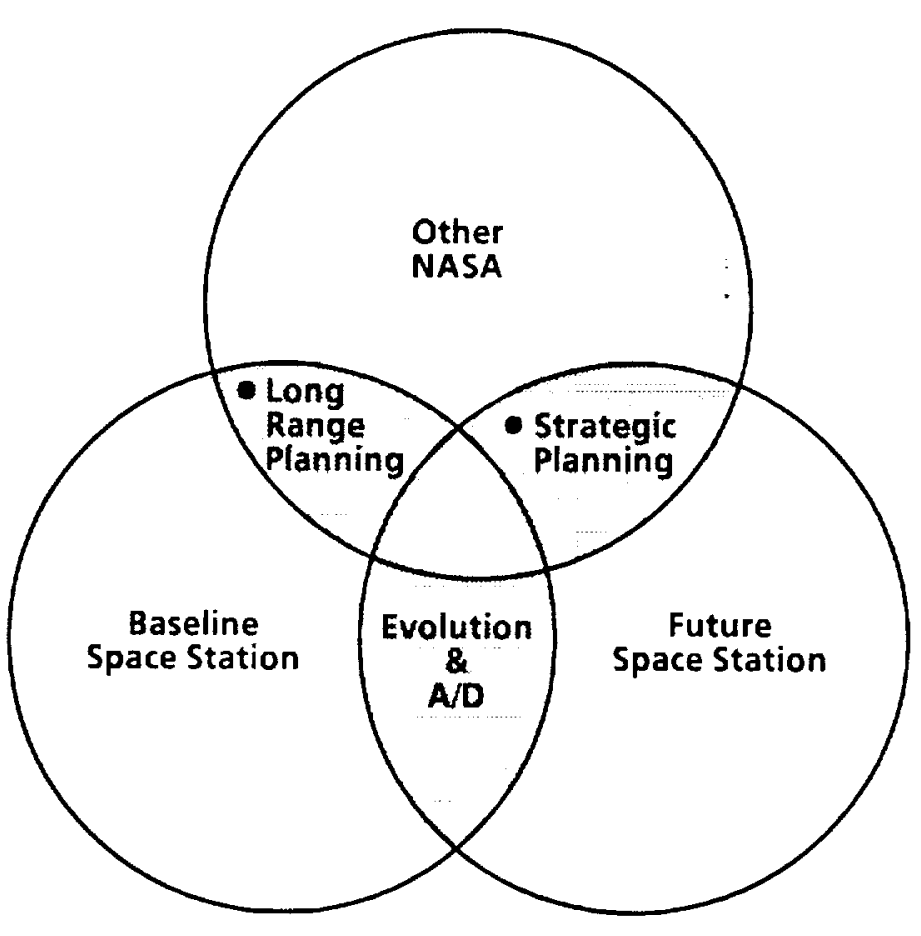

FIGURE 1. STRATEGIC / EVOLUTION PLANNING RELATIONSHIPS

\section{Evolution Paths and Modes}

Evolution planning is centered on a series of integrated studies of evolution paths and modes. Evolution paths, determined by user requirements, may be multidiscipline in nature or focused on a single discipline or new initiative. Evolution modes are options for the infrastructure to support the user requirements, i.e. to support the evolution paths. From these studies the near-term requirements, "hooks and scars" and technology needs, can be derived.

A variety of evolution paths, as shown in Figure 2. have been examined in workshops and studies. The objective of the evolution path studies is first to understand the requirements of a specific mission or type of missions. This is followed by an analysis of the interaction of the specific missions(s) with the mission complement on the baseline Space Station and with other potential evolution missions.

In fiscal year 1988 the evolution path studies will be focused on potential Space Station support for four new initiatives that are now being studied within NASA: "Humans to Mars" focuses on piloted missions to explore Mars and establish an outpost. "Lunar Base" has the objective of exploring the moon and establishing a base for the utilization of Lunar resources. "Planetary Exploration" includes the unmanned exploration of the planets, including the return of a sample from Mars. The goal of "Mission to Planet Earth" is to combine observations from sun-sychronous, low altitude, and geostationary orbits to obtain a scientific understanding of the entire earth system. The study of these four initiatives, encompassing a broad range of requirements, will contribute substantially to the general evolution knowledge base while providing specific information on requirements for the Space Station to support these missions. Additionally in 1988 studies of methods to increase Space Station efficiency and productivity will provide support for any potential evolution path. It is expected that a dominant focus in the area of increased productivity will be those technologies associated with system autonomy and robotics.

Optional evolution modes must be explored for each evolution path because the ultimate evolution infrastructure to accommodate the mission(s) will depend not only on the specific mission requirements but also on the other missions that are concurrently accommodated. Expansion of the baseline Space Station capabilities is usually considered as the first option. The multidiscipline, evolutionary design of the baseline Space Station allows it to be expanded, by the addition of resources (power, laboratory volume, etc.) or new facilities, to accommodate almost any new 


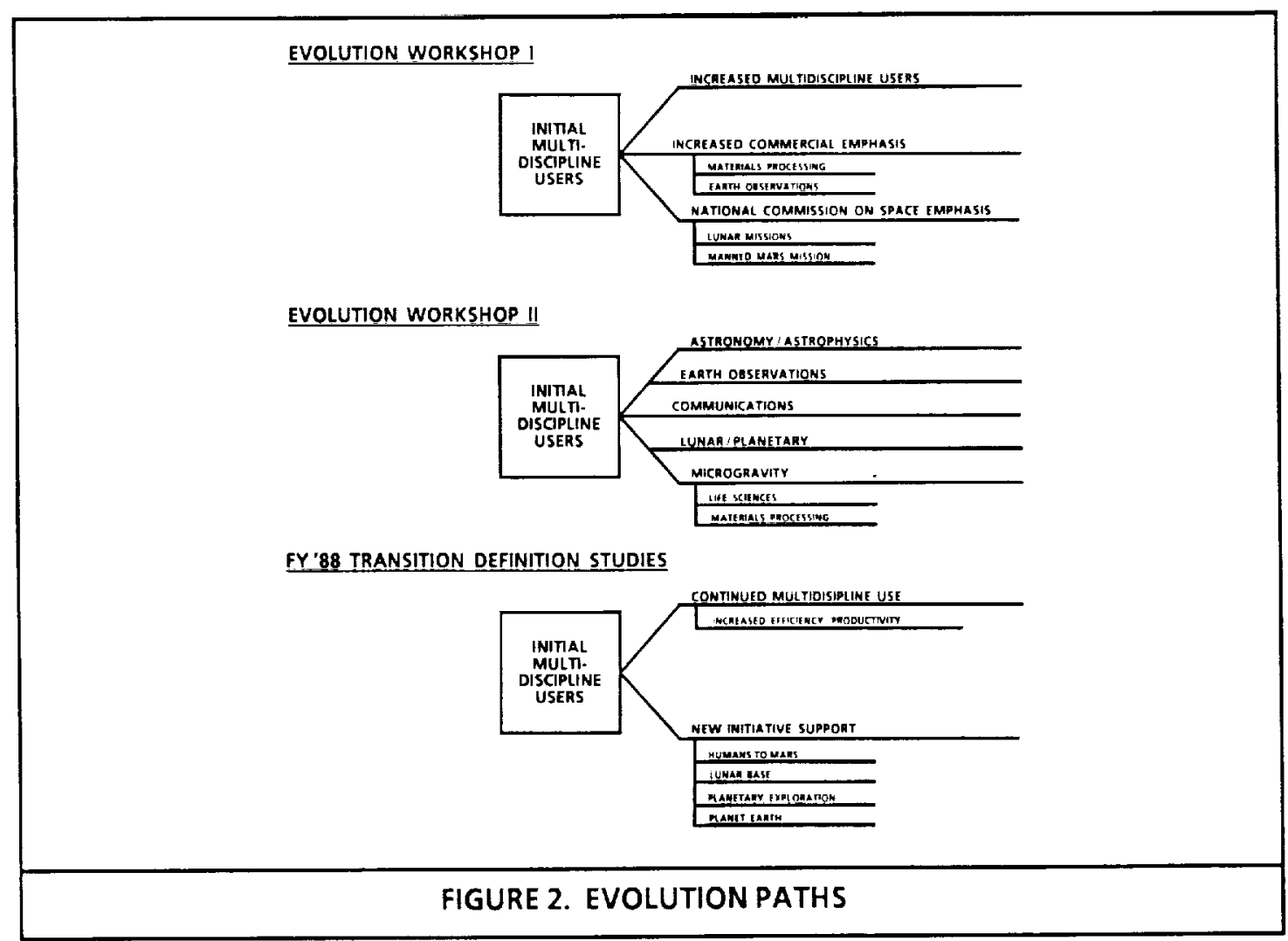

missions. More complex options, including the addition of platforms or a new manned base, are considered for several reasons: (1) operational conflicts may be created by the need to simultaneously accommodate many varying user requirements on one Station; (2) a dedicated facility may be desired to meet increases in specialized resource demands; and (3) a different orbit may be required for some missions. Figure 3 is a summary of the various evolution modes.
Consideration of potential operational conflicts led to the concept of "branching" as an evolution mode. "Branching" implies that specific types of user functions would be accommodated on one Space Station and other types of functions would be moved to another manned base or to platforms. The most common branching concept is for a "quiet" Space Station to accommodate microgravity and precision pointing experiments while another Station becomes a "transportation node"

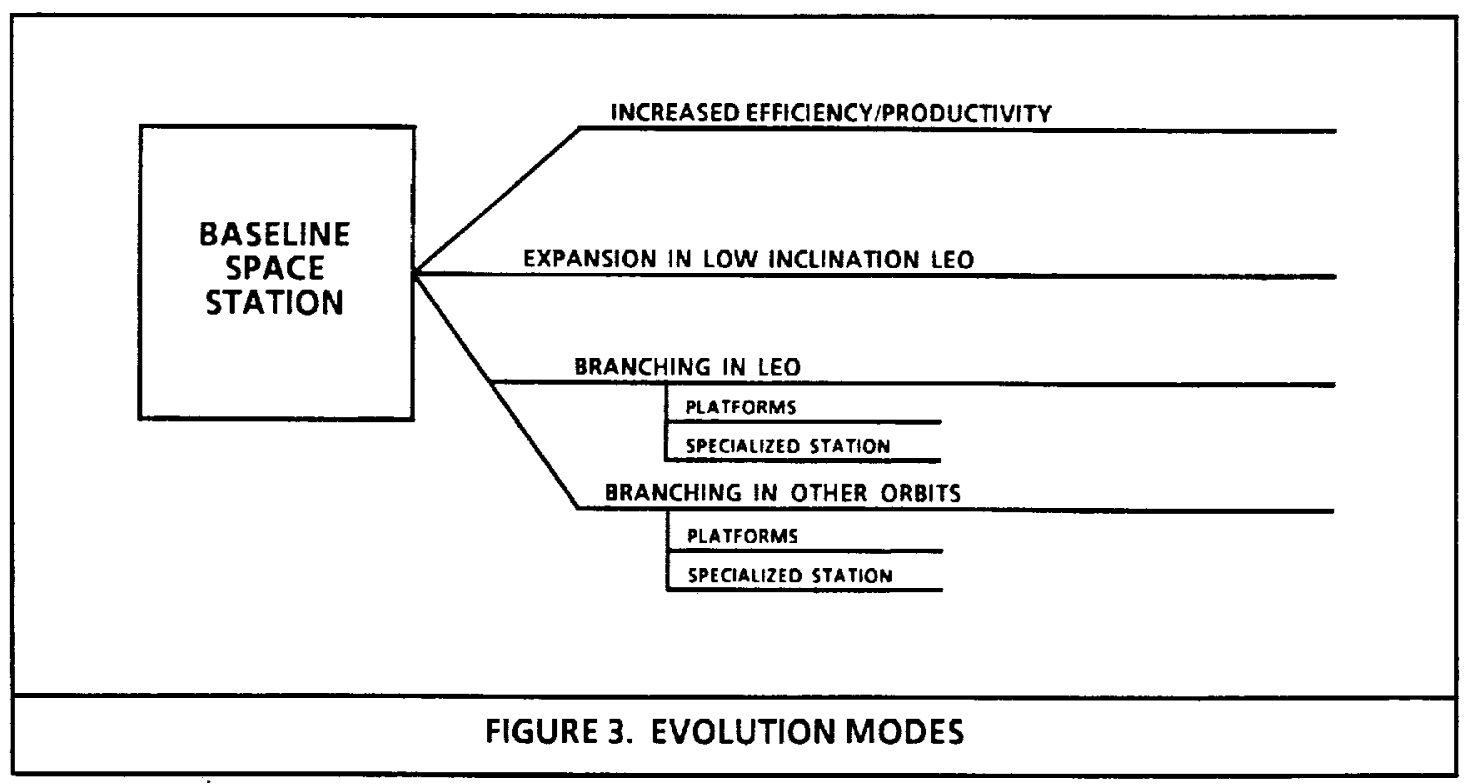


to support satellite servicing and deployment of high energy missions. Branching to a "spaceport" is an option to support the establishment of a Lunar base or a Mars outpost. Branching to "microgravity factories" on platforms, or on an intermittently manned base, is considered an option for commercial entities to aggressively pursue materials processing in space. Concepts, developed at the second Space Station Evolution Workshop, for a spaceport and for a intermittently manned microgravity Station are shown in Figures 4 and 5 .
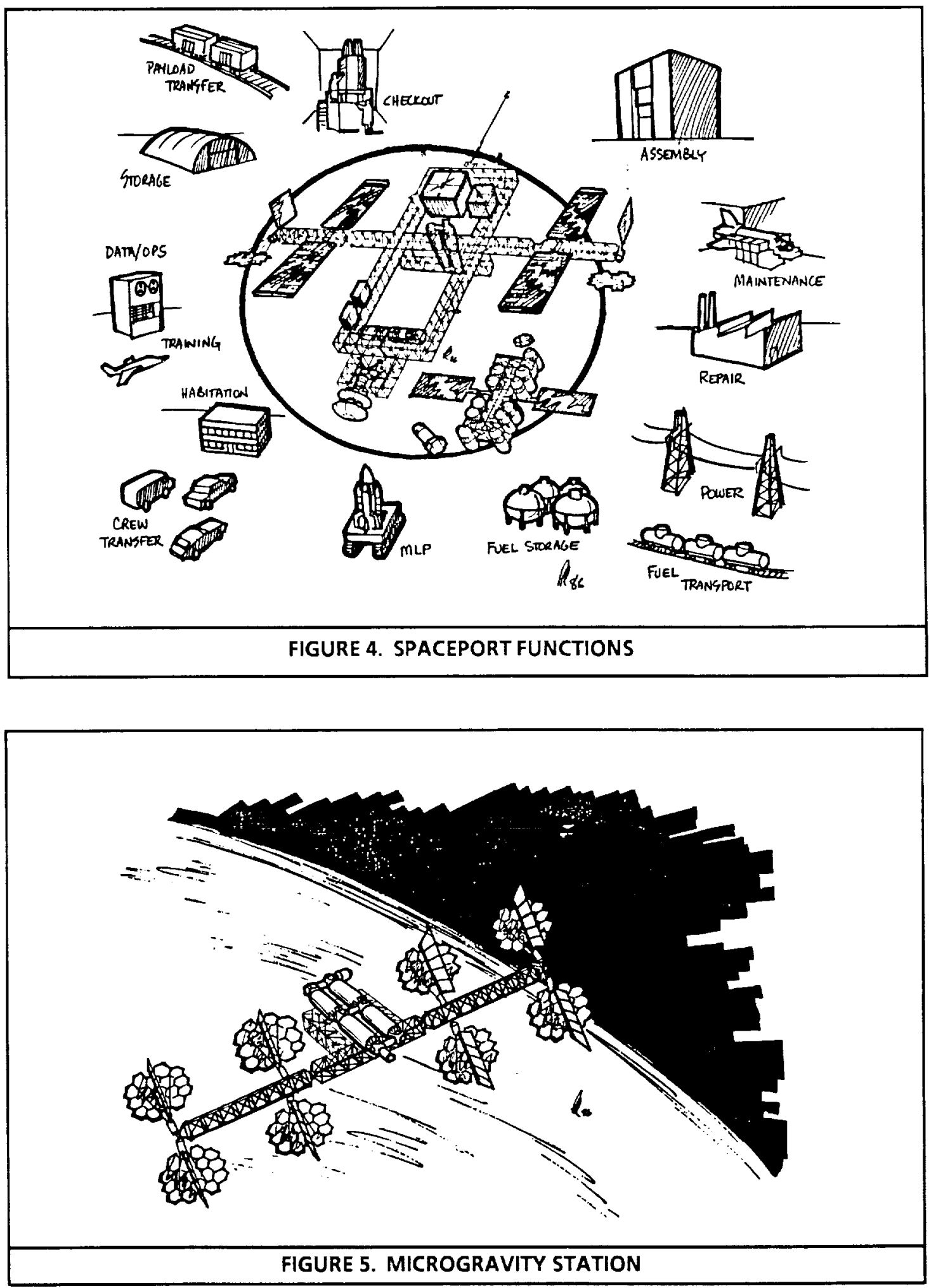
One evolution mode, "increases in efficiency and productivity", is independent of the evolution paths. The increases in efficiency and productivity are best exemplified by technology upgrades, i.e. the insertion or addition of new technologies as they become available. This mode is given high priority in initial evolution planning because it will contribute substantially to any evolution path and will increase the capability of the Space Station to serve users even if there is no expansion of the infrastructure. The initial studies in support of this evolution mode are concentrated on understanding what "technology transparency" means in the design of Space Station systems and subsystems and what provisions must be incorporated to make the Space Station "technology transparent". Special attention will be given to the capability to incorporate advanced automation and robotics

\section{Near-term Provisions for Evolution}

Evolution paths and evolution modes have been, and will continue to be, examined from several different viewpoints. The most interesting result to date is that certain high leverage requirements readily emerge from the studies regardless of the viewpoint. Certain technologies, such as automation and robotics and the techniques for the assembly of large structures on-orbit, are enabling or enhancing for many missions. "Hooks and scars" to allow increases in the Space Station power thermal, pressurized volume, data storage and transmission will facilitate most future missions. And most significant, although most difficult, are the "technology transparency" provisions to allow upgrades in space Station technologies and the incorporation of advanced automation. Addition. ally, study results emphasize the need for increased earth-to-orbit transportation that will support the additional logistics required for multidiscipline growth as well as the specific requirements for assembly and fueling of large spacecraft for Lunar or Mars missions

A methodology, illustrated in figure 6 , has been developed for further derivation of the high leverage requirements. The approach is to first select probable evolution paths and determine the enabling/enhancing provisions for those paths. Subsequent comparison of the required provisions and the technologies to support them will determine the elements of high commonality. These will be the focus of evolution planning. Some unique requirements, such as the long duration life support activities for a Mars mission, also emerge and must be considered on a case by case basis in the context of other NASA long range planning.

Technology needs, identified from the evolution studies, are one focus of the evolution advanced development program. Another focus is "tech. nology opportunities". The advanced development program will identify other technologies that have potential high payoff for the Space Station, and will work iteratively with the evolution planning process to assure appropriate incorporation. The associated management process is especially important in the area of technologies that can enhance efficiency and productivity. The productivity enhancements, that have been shown to be of benefit to all missions, will be emphasized in the fiscal year 1988 evolution advanced development program. This will include technology developments in robotics, system autonomy, and information systems, and investigations of the scarring required for advanced automation and other high technology systems.
- determination of common FACTORS FOR EVOLUTION PLANNING (ILLUSTRATIVE ONLY)

SPACE STATION ENHANCING/ ENABLING PROVISIONS

\section{$\downarrow$}

- RESOURCE GROWTH

-ETO TRANSPORTATION - HIGH ENERGY TRANSPORTATION -PLATFORM CAPABILITIES -ASSEMBLY/CONSTRUCTION/STAGING - AUTOMATION/ROBOTICS - LONG DURATION LIFE SUPPORT -SYSTEM RELIABILITYIAUTONOMY - SERVICING

-DATA STORAGETRAANSMISSION

-ENVIRONMENTAL CONTROL

-PROXIMITY OPERATIONS

-OUARANTINE FACILITIES

-TECHNOLOGY UPGRADES

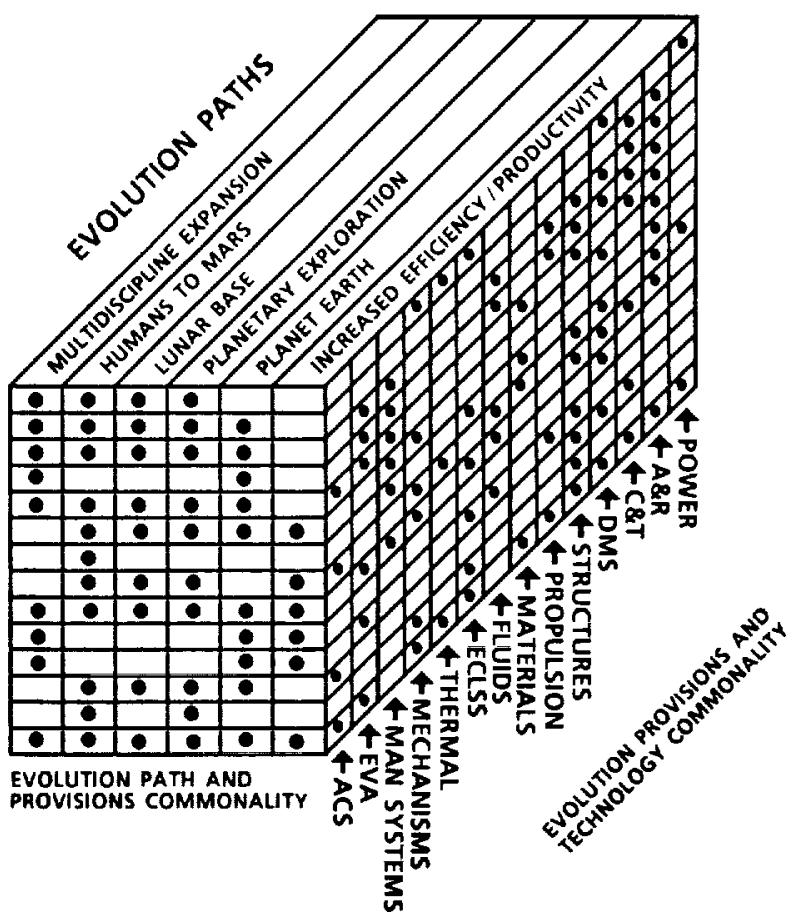

FIGURE 6. EVOLUTION PLANNING APPROACH 


\section{Current Issues and Future Plans}

The most difficult issue in the evolution aspects of the Space Station Program is "technology transparency". The Space Station will be designed for a thirty year lifetime on-orbit. Selection of system and subsystem designs will be made several years prior to the initial operational capability onorbit. During these thirty-plus years, current technologies will improve by orders of magnitude and new technologies will be developed. Some components of the initial Space Station may not even be available as replacement parts. "Technology transparency" has been discussed here as "enhancing", but it may also be "enabling" in terms of the on-orbit maintainability of the Space Station. Therefore, the efforts to understand how to incorporate "technology transparency" in the initial design may be crucial to the long term success of the Space Station Program.

The evolution planning strategy is summarized in Figure 7. In this paper we have discussed numerous evolution paths and modes. We have done so with the full knowledge that most of these will never occur. Evolution will be driven by both technical and political requirements. Indeed, it is possible that substantial growth of the initial Space Station will never occur. That does not negate the current responsibility to keep the options open -. to facilitate the growth if it is needed. And these options are exciting. The Space Station is a gateway to the exploration of the moon and planets, to tremendous increases in our understanding of the Earth, and to the accumulation of scientific knowledge of both intellectual and material value.

\section{References}

1. "Proceedings of the Space Station Evolution Workshop, Hilton National Conference Center. Williamsburg, Virginia, September 10-13, 1985", Office of Space Station, NASA Headquarters, Washington, DC.

2. "Proceedings of the Space Station Evolution Workshop. Williamsburg, Virginia, July 29 August 1, 1986", Office of Space Station, NASA Headquarters, Washington, DC.

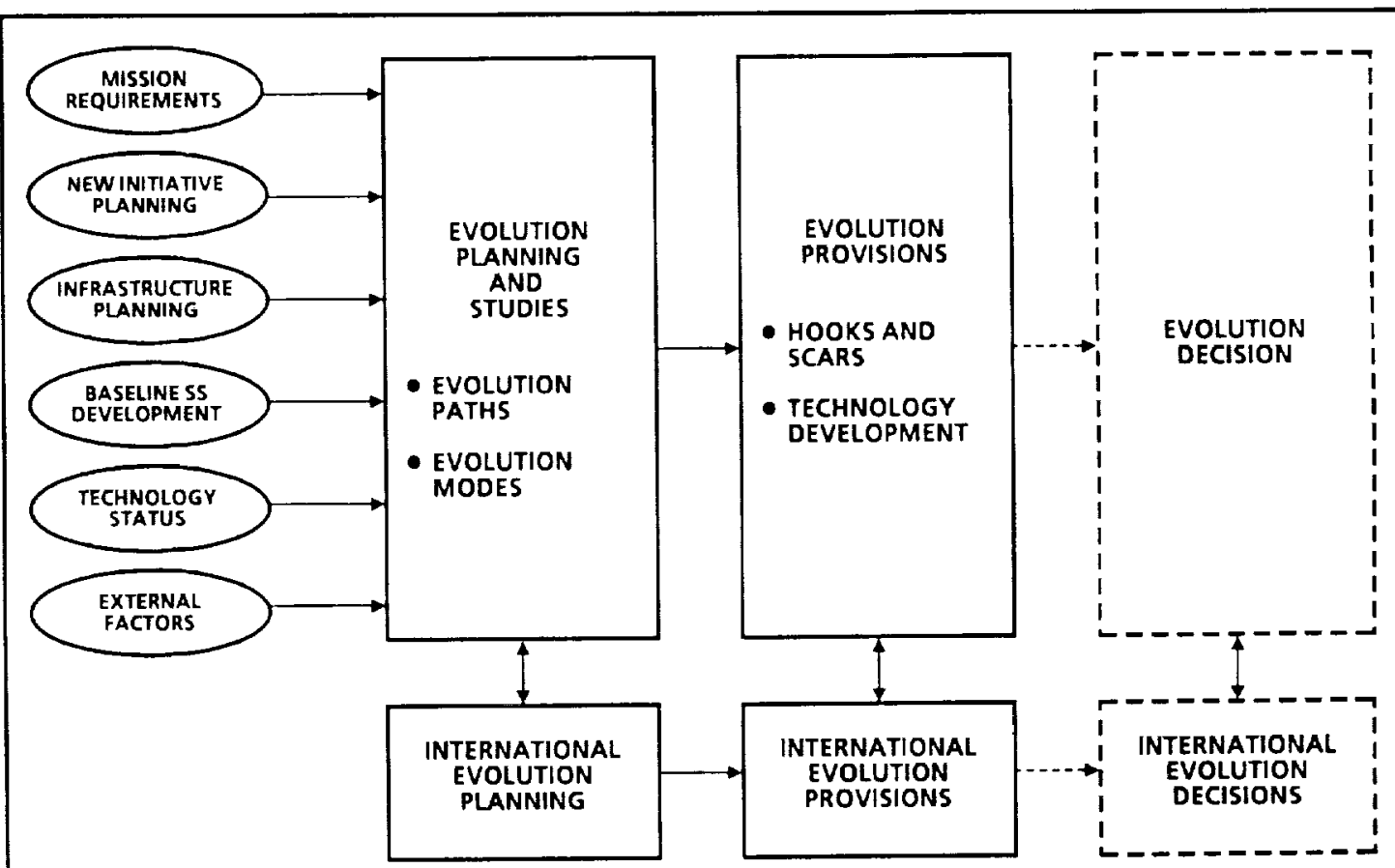

Recognize the Forces ... Understand the Options ... Keep the Options Open ... Facilitate the Changes ... 